\title{
Letter \\ Regression modelling in hospital epidemiology: a statistical note
} Martin Wolkewitz ${ }^{1}$, Jan Beyersmann ${ }^{1}$, Petra Gastmeier ${ }^{2}$ and Martin Schumacher ${ }^{1}$

\author{
${ }^{1}$ Institute of Medical Biometry and Medical Informatics, University Medical Center Freiburg, Stefan-Meier-Straße, D-79104 Freiburg, Germany \\ 2Institute of Hygiene and Environmental Medicine, Charité - University Medicine, Hindenburgdamm 27, 12203 Berlin, Germany
}

Corresponding author: Martin Wolkewitz, wolke@fdm.uni-freiburg.de

Published: 4 September 2008

Critical Care 2008, 12:427 (doi:10.1186/cc6991)

This article is online at http://ccforum.com/content/12/5/427

(c) 2008 BioMed Central Ltd

See related commentary by Barnett and Graves, http://ccforum.com/content/12/2/134, and see related research by Wolkewitz et al., http://ccforum.com/content/12/2/R44

Barnett and Graves [1], in their commentary on our report recently published in Critical Care [2], suggested that timediscrete methods should be used to address time-dependent risk factors and competing risks. In this letter we comment on two statements by those authors.

First, Barnett and Graves claim that, 'An alternative method to the competing risks model is a multistate model.' In fact, a multistate model is not an alternative to modelling competing risks, but a competing risks model is an example of a multistate model. This is explained in the tutorial by Putter and coworkers [3]. However, competing risks only model the time to first event and the event type (for example, time to nosocomial infection [NI]) or discharge/death, whatever comes first. To model subsequent events also, more complex multistate models are needed. Barnett and Graves give an example in which discharge/death events after $\mathrm{NI}$ are also modelled. However, such a complex multistate model is implicitly used in a competing risks analysis when timedependent risk factors are included. For example, in our report we also analyzed discharge and death as competing events and $\mathrm{NI}$ as a time-dependent covariate. Such a model analyses discharge/death events after NI.

Second, Barnett and Graves claim that pooled logistic regression has some advantages over Cox regression. In our intensive care unit setting, if data are collected day by day then both models are technically identical survival models and provide identical results, even though the Cox model is less restrictive. The Cox model is a very flexible regression model with potential extensions. Usually, hazard ratios are assumed to be constant, but the assumption of proportional hazards can be relaxed such that the regression coefficients may vary with time (see Martinussen and Scheike [4]). Time since NI can be included as an additional covariate in this model. Random effects may also be studied (see the discussion of frailty models in the book by Hougaard [5]). However, in this context it should be noted that standard logistic regression (one patient - one record) does not model time to event and might not appropriately include time-dependent risk factors.

In accordance with our primary report [2], Barnett and Graves [1] highlighted the need to take into account both time-dependent risk factors and competing risks when the impact of nosocomial infections on intensive care unit death/ discharge is the focus of interest. In addition, they highlighted important issues that would be worth studying and would be interesting for medical research. Extensions of the logistic and the Cox regression model are adequate models in which to study those complex medical questions.

\section{Competing interests}

The authors declare that they have no competing interests.

\section{References}

1. Barnett A, Graves N: Competing risks models and time-dependent covariates. Crit Care 2008, 12:134.

2. Wolkewitz M, Vonberg RP, Grundmann H, Beyersmann J, Gastmeier P, Baerwolff S, Geffers C, Behnke M, Rueden H, Schumacher M: Risk factors for the development of nosocomial pneumonia and mortality on intensive care units: application of competing risks models. Crit Care 2008, 12:R44.

3. Putter H, Fiocco M, Geskus RB: Tutorial in biostatistics: competing risks and multi-state models. Stat Med 2007, 26:23892430.

4. Martinussen M, Scheike T: Dynamic regression models for survival data. In Statistics for Biology and Health. New York, NY: Springer; 2006:205-213.

5. Hougaard P: Analysis of multivariate survival data. In Statistics for Biology and Health. New York, NY: Springer; 2006:215 ff. 